\title{
Evaluation of Knowledge and Psychomotor Skills of Lady Health Visitors about Immunization
}

\author{
Muhammad Rashid Anjum, ${ }^{1}$ Muhammad Arif Khan, ${ }^{2}$ Unsa Athar, ${ }^{3}$ Awais Raza, ${ }^{4}$ Ayesha Irfan, \\ Sarah Arif, ${ }^{6}$ Ahsan Mehmood, ${ }^{7}$ Arsalan Sikandar, ${ }^{8}$ Huda Iftikhar, ${ }^{9}$ Shireen Farrukh, ${ }^{10}$ Abdul \\ Rafay, ${ }^{11}$ Tayyaba Khadim, ${ }^{12}$ Zoraiz Mushtaq $^{13}$
}

\section{Abstract}

Adequate training of Lady Health Visitors is foundational for the prosperity of community health worker scheme in Pakistan.

Objective: To determine the deficiencies in the training Lady Health Visitors by assessing their knowledge and psychomotor skills.

Study Design: Cross - sectional study.

Study Duration and Place: The study was conducted in 6 - month duration in Community Medicine Department, KEMU, Lahore.

Subjects and Methodology: A cross - sectional study was carried out at Model Maternal and Child Care Centre, Montgomery Road, Lahore. A total of 100 Lady Health Visitors were selected on the basis of laid down inclusion criteria. Data was collected through a pretested questionnaire and analyzed by SPSS version

\footnotetext{
1 MHPE (UHS) Lahore PG Student

2 Former APMO Department of Community Medicine, KEMU, Lahore

3-13 $4^{\text {th }}$ Year MBBS Student, KEMU
}

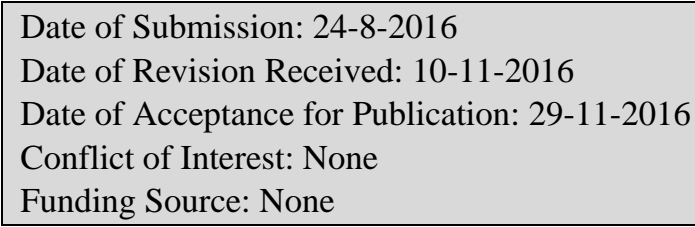

\section{Contribution}

All Authors have contributed in Study Design, Data Collection, Data Analysis, Data Interpretation, Manuscript Writing and Approval.
16.0.

Results: LHVs had an adept comprehension of vaccinations of 9 diseases covered by EPI (99\%). They had adequate knowledge of antenatal vaccines $(64 \%)$, perinatal vaccines $(87 \%)$ and postnatal $(77 \%)$ vaccines, indicating good recall. But they had less grasp on the method of filling vaccination cards $(30 \%)$ and counselling about side effects of vaccines (17\%) showing low psychomotor skills. However, recall and psychomotor skills showed significant correlation ( $\mathrm{p}<0.05$ ).

Conclusion: Our study concluded that there is a significant correlation between recall and psychomotor skills of our Lady Health Visitors. By analyzing the strengths, weaknesses, opportunities and threats of the training of Lady Health Visitors, our study showed that they had better recall but lower psychomotor skills. Hence modifications are required in their training to improve psychomotor skills.

Keywords: Lady Health Visitors, Recall, Psychomotor skills.

\section{Introduction}

Primary Health Care (PHC) has been recognized all over the world as an unparalleled standard for the provision of extensive health services particularly to the impoverished and economically poor sectors of the community. ${ }^{1}$ Of the eight essential components of PHC, immunization serves to eliminate major infectious diseases, massively improving overall health globally. To provide this essential primary health service in the community and to accomplish health for all in the rural and urban slum areas, Government instituted Pakistan Nursing council for registering and regulating 
Lady Health Visitors (LHVs). ${ }^{2}$ Since $1951,{ }^{3}$ Lady Health Visitors duties include two main subjects, Immunization and Family Planning. The role of LHVs, after a two - year diploma, is to administer vaccines, manage normal labour and delivery cases, treat common diseases in women and children, educate and counsel regarding family planning, identify complications of any disease and carry out an efficient referral to concerned specialist. ${ }^{4}$ Proper training of community health workers all over the world is essential for the provision of health care. ${ }^{5}$ Achievement of adequate training of Lady Health Visitors has a direct influence in provision of preventive, curative and rehabilitative services to the community.

A research paper from Iran concluded that the coverage of all vaccines has continuously reached $99 \%$ due to various community health workers. ${ }^{6}$ Meanwhile in Gambia. Another research done stated that BCG uptake was high with $95 \%$ coverage in all areas and that of DPT was $93.2 \%$ due to community health workers. ${ }^{7}$ According to CJ Morrel, health visitors in UK have been trained to provide psychologically informed intervention as well. ${ }^{8}$ A research conducted in India showed that $23.34 \%$ of Lady Health Visitors showed "excellent knowledge", $52.32 \%$ of them had "good knowledge" and $23.34 \%$ had "average knowledge" on majority of the subjects taught to them. ${ }^{9}$ A research paper stated that $78 \%$ had adequate knowledge to practice individually. ${ }^{10}$ According to a study, the introduction of maternal and child health intervention progamme led to a significant improvement $(p<0.05)$ in the performance skills of lady health visitors related to antenatal, postnatal and newborn care. ${ }^{11}$ Research done in Islamabad showed that $80 \%$ of community health workers described their communication skills as moderately sufficient and wanted improvement. ${ }^{12}$ In a study a large number of LHVs claimed on not being fully content with the immunization service and are of the view that there is an imbalance between the number of vaccinators and expanse of population they attend to. ${ }^{13}$ In attempts to highlight the factor affecting the efficacy of LHVs, a study showed that $71 \%$ of LHVs and midwives have formal training regarding neonatal resuscitation. ${ }^{14} \mathrm{~A}$ research demonstrated that there is significant relation between education of LHVs and their performance. ${ }^{15}(\mathrm{p}<0.05)$.

Our study target was to evaluate the training of LHVs in terms of their knowledge and psychomotor skills. Hence we determined the shortcomings of the LHVs' training system and so that they could be imp- roved by working on the identified areas for improvement.

\section{Methodology}

Our study was a Cross Sectional Study with SWOT analyses. The study setting was Model Maternal and Child Care Centre, Montgomery Road, Lahore. The study was conducted for a duration of 6 months with a sample size of 100 individuals. The sample size calculations were based on $80 \%$ power of test and $95 \%$ confidence interval and $10 \%$ difference in Knowledge and psychomotor skills. We also adjusted $10 \%$ for the probability of drop out during research. ${ }^{14}$ The sampling technique used was Simple random sampling. In Sample selection criteria, the Inclusion Criteria were: regular student of Public Health School, Montgomery Road, Lahore and student of LHV class only. Those students were excluded who failed to give consent. The Data Collection Procedure used by all members of the batch was the data collection tool (pre-tested questionnaire).

The knowledge of LHVs was assessed by asking them about different antenatal, perinatal and postnatal vaccines, efficacy of vaccines as well as importance of vaccination card.

The psychomotor skills were evaluated by asking them to demonstrate different routes of administration of vaccines, filling a vaccination card and counselling about side effects of vaccines and missed doses.

These were compared with the standard guidelines given by World Health Organization in the Vaccination Summary Table ${ }^{16}$ and Vaccination Safety Course. $^{17}$

The strengths were studied under knowledge about vaccines and their attendance in class.

The weaknesses were studied by assessing their psychomotor skills, use of newer technologies in training, and methods of training.

In opportunities we analyzed their hands-on training and community work, and under threats we discussed security issues, social stigma and lesser job opportunities.

The obtained data was analyzed by Statistical package for social scientist (SPSS) version 16. The synopsis was approved by the ethical committee. Proper Consent was taken from the subjects. 


\section{Results}

The demographic profile of the LHVs showed distribution in age (Figure 1.) and socioeconomic status (Figure 2.) only. All the LHVs belonged to urban areas.

Our study tested the training of LHVs on the basis of a number of variables that can be divided into two groups, their recall and psychomotor skills, as shown in Table $1.64 \%$ of LHVs had knowledge about antenatal vaccines, $87 \%$ about perinatal and $77 \%$ about postnatal. $62 \%$ of them had knowledge regarding the importance of vaccination card. Showing that a total of $73 \%$ of LHVs had recall knowledge. While demonstrating psychomotor skills, $96 \%$ could demonstrate administration of vaccine through different routes, $30 \%$ could fill a vaccination card, $73 \%$ showed how to counsel regarding a missed dose, and only $17 \%$ showed counselling about side effects. Thus a total of $54 \%$ of LHVs demonstrated adequate psychomotor skills. To study the relation between recall and psychomotor skills, Pearson correlation was calculated as shown in Table 2.

The p-value calculated by Pearson correlation comes out to be 0.01 . Hence there is a significant linear positive relationship between recall and psychomotor skills of LHVs. Increasing recall knowledge will in turn increase psychomotor skills. Considering the above relation, a SWOT analysis was done to figure out the strengths, weaknesses, opportunities and threats of LHVs training which can be then utilized to improve their knowledge and psychomotor skills. The SWOT analysis has been summarized in Table 3.

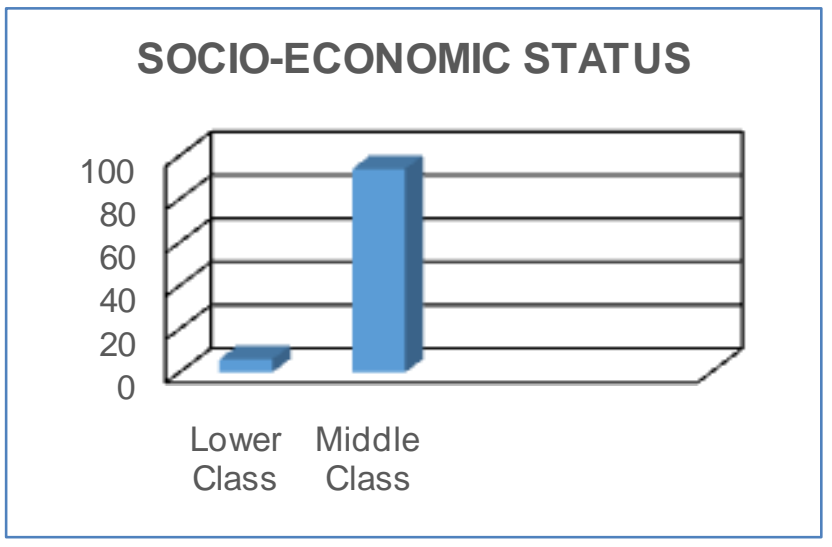

Fig. 1: Distribution of socioeconomic status of LHVs.

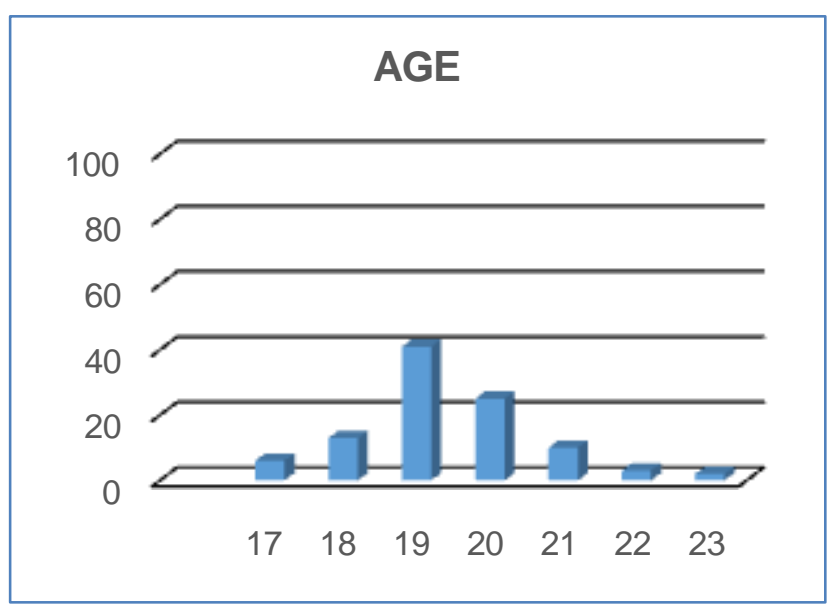

Fig. 2: Distribution of age of LHVs.

Table 1: Variables studied to assess recall knowledge and psychomotor skills of LHVs.

\begin{tabular}{|l|c|l|c|}
\hline \multicolumn{1}{|c|}{ Variable } & $\begin{array}{c}\text { RECALL (\% of LHVs } \\
\text { having that Knowledge) }\end{array}$ & Variable & $\begin{array}{l}\text { Psychomotor Skills (\% of } \\
\text { LHVs having that Skill) }\end{array}$ \\
\hline $\begin{array}{l}\text { Knowledge about Antenatal } \\
\text { Vaccines }\end{array}$ & 66 & $\begin{array}{l}\text { Demonstration of different } \\
\text { Routes of administration }\end{array}$ & 96 \\
\hline $\begin{array}{l}\text { Knowledge about Perinatal } \\
\text { Vaccines }\end{array}$ & 87 & Filling a Vaccination Card & 30 \\
\hline $\begin{array}{l}\text { Knowledge about Postnatal } \\
\text { Vaccines }\end{array}$ & 77 & $\begin{array}{l}\text { Counselling about missed } \\
\text { dose }\end{array}$ & 73 \\
\hline $\begin{array}{l}\text { Knowledge about Vaccination } \\
\text { Card }\end{array}$ & 62 & $\begin{array}{l}\text { Counselling about side } \\
\text { effects of vaccines }\end{array}$ \\
\hline Total (\%) & 72.8 & Total (\%) & 17 \\
\hline
\end{tabular}


Table 2: Pearson Coefficient Correlation between variables.

\begin{tabular}{|c|c|c|}
\hline Variables & Deviation Score & Coefficient of Determination $\left(r^{2}\right)$ \\
\hline Recall knowledge and psychomotor skills & 38.1 & $0.01 *$ \\
\hline
\end{tabular}

*Correlation is significant at the 0.01 level (2-tailed)

Table 3: SWOT Analysis of LHV Training.

\begin{tabular}{|c|c|c|c|}
\hline Strengths & Weaknesses & Opportunities & Threats \\
\hline $\begin{array}{l}100 \% \text { attendance of all } \\
\text { LHVs in classes. } \\
\text { Their recall knowledge, } \\
\text { regarding the importance } \\
\text { vaccination cards }(62 \%), \\
\text { the } \\
\text { Their knowledge, } \\
\text { regarding antenatal } \\
(64 \%), \text { perinatal }(87 \%), \\
\text { postnatal }(77 \%) \text { vaccines. }\end{array}$ & $\begin{array}{l}>\begin{array}{l}\text { Overall lower psychomotor } \\
\text { skills than recall }\end{array} \\
>\quad \begin{array}{l}\text { Lack of newer technologies } \\
\text { in class and lab }\end{array} \\
>\quad \text { Unsatisfactory class test } \\
\text { system } \\
>\quad \text { Lack of student-teacher } \\
\text { interactive teaching } \\
>\quad \text { Lack of training sessions } \\
\text { other than regular classes. }\end{array}$ & $\begin{array}{l}\text { Hands-on training on } \\
\text { patients visiting } \\
\text { MCHC Centre } \\
>\quad \begin{array}{l}\text { Community work via } \\
\text { trips to BHU and RHC }\end{array}\end{array}$ & 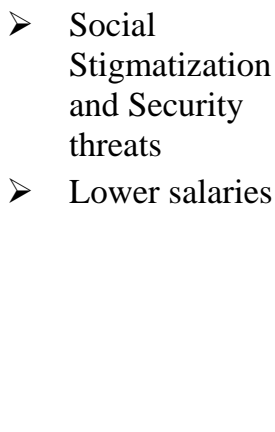 \\
\hline
\end{tabular}

The strengths of LHVs' training included a100\% attendance of all LHVs in classes. Their recall knowledge, regarding the importance vaccination cards $(62 \%)$, the antenatal $(64 \%)$, perinatal $(87 \%)$, postnatal (77\%) vaccines, was their strength as well.

However, the weaknesses of their training were quite a few. Though by increasing the recall knowledge the psychomotor skills could be improved (positive correlation), the psychomotor skills as a whole were lower. Only $17 \%$ of them showed counselling skills about the side effects of the vaccines. $30 \%$ knew how to fill in vaccination cards and $73 \%$ knew how to counsel about a missed dose. Along with that, All of the LHVs were of the notion that the lectures were not aided with any multimedia and there was no internet facility on campus. Thus lack of newer technology was a weakness in their training. $38 \%$ of LHVs also said there was a lack of up-to-date apparatus in their laboratories. Deficiencies also lied in training methodologies. Only $50 \%$ of them were satisfied with their system of class tests and $76 \%$ of them said that there was a lack in student-teacher interactive learning. 24\% of LHVs also said that there were no extra sessions conducted by teachers apart from regular lectures, to answer their queries.

The opportunities provided to LHVs included and hands-on training on patients in the affiliated Model Maternal and Child Care Centre Outdoor Department. But $69 \%$ of the students thought that this opportunity was deficient because of the load of patients, only few students are able to interact and deal with patients. Community work opportunities were also provided to the students through trips to Basic Health Units and Rural Health Centers and working with the LHVs on duty there. But due to mismanaged schedules, only $20 \%$ of the LHVs get this opportunity.

The threats that LHVs have to face include social stigmatization of their jobs. $69 \%$ of the LHVs thought that females working in rural areas are frowned upon by the local residents and considered inferior and this posed a serious security threat. $77 \%$ of LHVs though that inadequate salaries for LHVs is also a threat to their training as it is causing lesser people to take admission in the LHV course.

\section{Discussion}

It is evident by a number of researches that LHVs and other community health workers led to an increased delivery of health care services to the communities. ${ }^{6,7}$ To ensure this health care delivery, training systems are of prime importance. ${ }^{5}$ A research shows that by educating LHVs in a proper way, we can enhance their performance. ${ }^{15}$ In our research, it becomes evident that the trainingof LHVs requires modifications for improvement in their psychomotor skills.

Our results show a significant correlation ( $\mathrm{p}<$ 0.05 ) between recall knowledge and psychomotor ski- 
lls which is similar to another research ${ }^{11}$ which showed that an intervention training programme led to a significant $(\mathrm{p}<0.05)$ increase in performance skills of LHVs. Thus we can increase their psychomotor skills by increasing recall knowledge.

But to increase recall as well as psychomotor skills, the deficiencies in their training system have to be removed. The deficiencies have been demonstrated by our SWOT analysis.

If we talk about the strengths of LHVs' training system, according to a study, in other countries ${ }^{9}$ only $23.34 \%$ of LHVs were found by researchers to have excellent knowledge but according to our research, the current training being used in our setting enables $73.8 \%$ LHVs to have recall knowledge about various entities involving vaccinations. A research ${ }^{18}$ on Lady Health Workers (LHWs) showed that $49 \%$ and $39 \%$ of LHWs showed knowledge about antenatal care and vaccination respectively, while our research regarding LHVs showed that $64 \%$ and $77 \%$ of them knew about antenatal and post-natal vaccines.

Our study also showed that LHVs are keen to study which is demonstrated by their $100 \%$ attendance.

To our knowledge no study so far has focused on vaccination cards, which is an important aspect for LHVs' practice regarding immunization. Our study showed that $62 \%$ LHVs knew about vaccination cards. Teachers must focus on this point and should ensure that all of them should at least have an idea about a vaccination card.

Evaluating the psychomotor skills of LHVs showed that LHVs had less psychomotor skills as compared to their knowledge, which bears similarities with a research done on LHWs as well (only $49 \%$ of LHWs were able to demonstrate skills regarding vaccination). ${ }^{18}$ Another research also showed that only 15 out of 22 community health workers showed clinical competence. ${ }^{19}$ A research ${ }^{14}$ showed that $71 \%$ LHVs and midwives had formal neonatal resuscitation training due to the importance it holds in their clinical practice. But our research demonstrated that the only worth mentioning skill our LHVs (96\%) possessed was being able to administer vaccines through different routes.

Talking about the vaccination cards, only $30 \%$ of LHVs in our research were able to fill a vaccination card, which is a weakness of their training system. By our evaluation we also came to know that lesser LHVs had the skill of counselling about side effects of vaccines $(30 \%)$ and missed dose (73\%). This aspect of LHVs skill is not well researched.
Further weaknesses in their training systems include complete absence of multimedia, internet facility and latest apparatus in their laboratories. In a research, internet and posters has been pointed out as a source of knowledge about vaccines. ${ }^{20}$ Since our LHV students did not have any access to the internet facility, this is a deficiency in their training.

Researches done in other cities stated that $80 \%$ of LHVs wanted improvement in the training systems ${ }^{12}$ which bears similarities to our results in which $76 \%$ LHVs describe dissatisfaction with their training. 50\% LHVs in our research were also dissatisfied with their class tests system. They were of the view that more tests should be conducted for a better learning, which is similar to another research ${ }^{10}$ which showed that performance can be enhanced by continuously refreshing knowledge.

Our research also indicated that the teachers did not hold extra classes/sessions for students to talk to them about their profession generally and immunization specifically. $24 \%$ of LHVs were of the notion that extra sessions should be conducted for students in order to guide them and answer their questions. A similar research indicated the need of mentorship and counselling for the betterment of $\mathrm{LHVs}^{10}$ because mentorship and counselling boost up the motivation of students to work better and hence performance is increased.

A SWOT analysis done on the National Program of Family Planning and Primary Healthcare ${ }^{[21]}$ indicated that community work of health workers has always been valuable in the absence of skilled professionals. Our research showed that LHVs student did get an opportunity to work at community level by their trips to Basic Health Units and Rural Health Centers where they worked under the supervision of on duty LHVs. The supervision of on duty is crucial as lack of supervision leads to poorer performances of LHVs as shown by a research. ${ }^{19}$

However, this opportunity in their training system also had a deficiency. Only $20 \%$ of LHVs were able to avail this opportunity due to mismanaged schedules.

Another opportunity provided in the training system of LHVs is hand-on training. The LHVs are taken to Model Maternal and Child Care Centre Outdoor Department where they practiced dealing with patients. This deficiency of this opportunity liedin the fact that only a few students were actually able to get a chance to talk to the patients individually because of the load of patients. This is similar to a study done on working LHVs ${ }^{13}$ who complained about the load of the 
population they deal with.

The threats that our LHVs faced included social stigmatization. The threats that LHVs have to face include social stigmatization of their jobs. $69 \%$ of the LHVs thought that females working in rural areas are frowned upon by the local residents and considered inferior and this posed a serious security threat. This result bears similarities to another one ${ }^{10}$ in which $34.1 \%$ of LHV studentsstated that their gender was problematic for them to practice. ${ }^{10}$ The same study also revealed that $47.7 \%$ LHV students were of the view that their professional life would be a stressful one.

Another threat faced by our LHVs was lesser salaries and lesser job opportunities in the government sector. $77 \%$ of LHVs in our research were concerned about their salaries and said that this threat caused lesser people to take admission in LHV diploma. Similar results have been shown by another research ${ }^{10}$ which showed that $69.7 \%$ of LHVs students were worried about their future earnings.

Summarizing the above discussion, we can see that the results of our research and by comparison with other researches indicate a number of deficiencies in LHVs training system. By evaluating their knowledge and psychomotor skills we came to know that attention must be paid on practical learning skills. Theoretical knowledge should be approved as well as this will also increase the psychomotor skills.

Deficient technologies in their training centres should also be catered to. Teachers should accept their responsibility as mentors. They should implement innovative and interactive methods of teaching and should also guide the students regarding their profession in a motivating manner.

Last but not the least, the government should increase the salaries of LHVs and should implement a social awareness campaign to help eradicate the social stigma that lies with LHVs working in rural areas.

\section{Conclusion}

Our study concluded that there is a significant correlation between recall and psychomotor skills of our Lady Health Visitors. By analyzing the strengths, weaknesses, opportunities and threats of the training of Lady Health Visitors, our study showed the of Lady Health Visitors had a better recall but lower psychomotor skills. Hence modifications are required in their training to improve psychomotor skills.

\section{References}

1. Hafeez A, Mohamud B, Shiekh M, Shah S, Jooma R. Lady health workers programme in Pakistan: challenges, achievements and the way forward. J Pak Med Assoc. 2011 Mar; 61 (3): 210-5.

2. Pakistan Nursing Council [Internet]. Pakistan: United States Agency for International Development; 2013 [updated 2013 June 10; cited 2016 May 05]. Available from: http://www.pnc.org.pk/

3. Upvall MJ, Sochael S, Gonsalves A. Behind the mud walls: The role and practice of lady health visitors in Pakistan. Health care for women international, 2002 Jul. 1; 23 (5): 432-41.

4. Majumdar B, Amarsi Y, Carpio B. Pakistan's community health workers. The Canadian Nurse, 1997 May; 93 (5): $32-4$

5. World Health Organization: Community Health Workers: What do we Know about them? - The state of the Evidence on Programs, Costs and Impact on Health Outcomes of Using Community Health Workers. Geneva: WHO; 2007.

6. Arefi Z, Kazemi Z, Shaahmadi Z, Mahmoudi S, Shaahmadi F. The Trend of the Extended Programme of Immunization (EPI) Iran from the Beginning (1984) to 2013. Int J of Pediatr [Internet]. 2015 Jul [cited 2016 Feb 20]; 3(19):4-1. Available from:

7. https://www.researchgate.net/publication/281209630_T he_Trend_of_the_Extended_Program_of_Immunizatio n_EPI_in_Iran_from_the_Beginning_1984_to_2013

8. Scott S, Odutola A, Mackenzie G, Fulford T, Afolabi $\mathrm{M}$, Jallow $\mathrm{Y}$ et al. Coverage and Timing of Children's Vaccination: An Evaluation of the Expanded Programme on Immunisation in The Gambia. PLoS ONE, 2014; 9 (9): e107280.

9. Morrell CJ, Ricketts T, Tudor K, Williams C, Curran J, Barkham M. Training health visitors in cognitive behavioural and person - centred approaches for depression in postnatal women as part of a cluster randomised trial and economic evaluation in primary care: the Ponder trial. Primary health care research and development, 2011; 12 (01): 11-20.

10. Thomas A. Leena K. Bhattacharaya C. Knowledge on Supervision, Attitude Towards Supervisory Responsibilities and Factors Affecting Supervision in the Community among Health Assistant Females/Lady Health Visitors (LHVs) in Dakshina Kannada District, Karnataka. Int J Nurs Educ. 2015; 7 (3): 36-39.

11. Siddiqui S. Shah N. Ayub R. Khan N. 'Student Lady Health Visitors': Their Stress Profile and Willingness to Practice. J Ayub Med Coll Abbottabad, 2012; 24: 3-4. Availabe from: https://www.researchgate.net/publication/261136925_ \%27Student_Lady_Health_Visitors\%27_their_stress_pr ofile_and_willingness_to_practice

12. Oxford Policy Management. Lady Health Worker Pro- 
gramme: External Evaluation of the National Programme for Family Planning and Primary Health Care.: Canadian International Development Agency (CIDA); 2009. Available from:

13. http://www.opml.co.uk/sites/default/files/Lady\%20Heal th\%20Worker\%20Programme $\% 20$ -

$\% 204$ th\%20Evaluation\%20$\%$ 20Summary\%20of\%20Results.pdf

14. Mansuri F, Baig L. Assessment of immunization service in perspective of both the recipients and providers. J Ayub Med Coll Abbottabad, 2003; 15 (1).

15. Haq Z, Iqbal Z, Rahman A. Job stress among community health workers: a multi-method study from Pakistan. Int J Ment Health Syst. 2008; 2 (1): 15.

16. Onprasonk W. Suwattana O. Harun- Or-Rashid M. Sakamoto J. Healthcare worker's knowledge and practices regarding expanded program on immunization in Kalasin, Thailand. Nagoya J Med Sci. 2011 Aug; 73 (34): 177-85. Available from:

https://www.researchgate.net/publication/51653095_He althcare_workers'_knowledge_and_practices_regarding _expanded_program_on_immunization_in_Kalasin_Th ailand

17. Lopes et al.: Community health workers: to train orto restrain? A longitudinal survey to assess the impact of trainingcommunity health workers in the Bolama Region, Guinea - Bissau. Human Resources for Health, 2014; $12: 8$.

18. WHO | E-learning course on Vaccine Safety Basics [Internet]. WHO | E-learning course on Vaccine Safety Basics. World Health Organization; [cited 2016Nov10]. Available from: http://www.who.int/vaccine_safety/initiative/tech_supp ort/ebasic/en/

19. WHO recommendations for routine immunization summary tables [Internet]. World Health Organization. World Health Organization; [cited 2016 Nov 10]. Available from:

http://www.who.int/immunization/policy/immunization tables/en/

20. Khan M, Saba N, Anwar S, Baseer N, Syed S. Assessment of knowledge, attitude and skills of lady health workers. Gomal J Med Sci. 2006 Jul - Dec; 4 (2): $57-$ 60. Available from:

https://www.researchgate.net/publication/228507330_A ssessment_of_Knowledge_Attitude_and_Skills_of_Lad y_Health_Workers

21. Ashwell H, Freeman P: The clinical competency of community health workers in the eastern highlands province of Papua New Guinea. PNG Med J. 1995, 38: 198-207.

22. Khan MU. Ahmad A. Akeel T. Akbar N. Salman S. Idress J. A Cross-sectional Survey of Healthcare Workers on the Knowledge and Attitude towards Polio Vaccination in Pakistan. PL8988oS One, 2015 Nov. 11; 10 (11). Available from: http://www.ncbi.nlm.nih.gov/pubmed/26559184

23. Wazir et al.: National program for family planning and primary health care Pakistan: a SWOT analysis. Reproductive Health, 2013; 10: 60. Available from: https://www.researchgate.net/publication/258851980_N ational_program_for_family_planning_and_primary_he alth_care_Pakistan_A_SWOT_analysis 